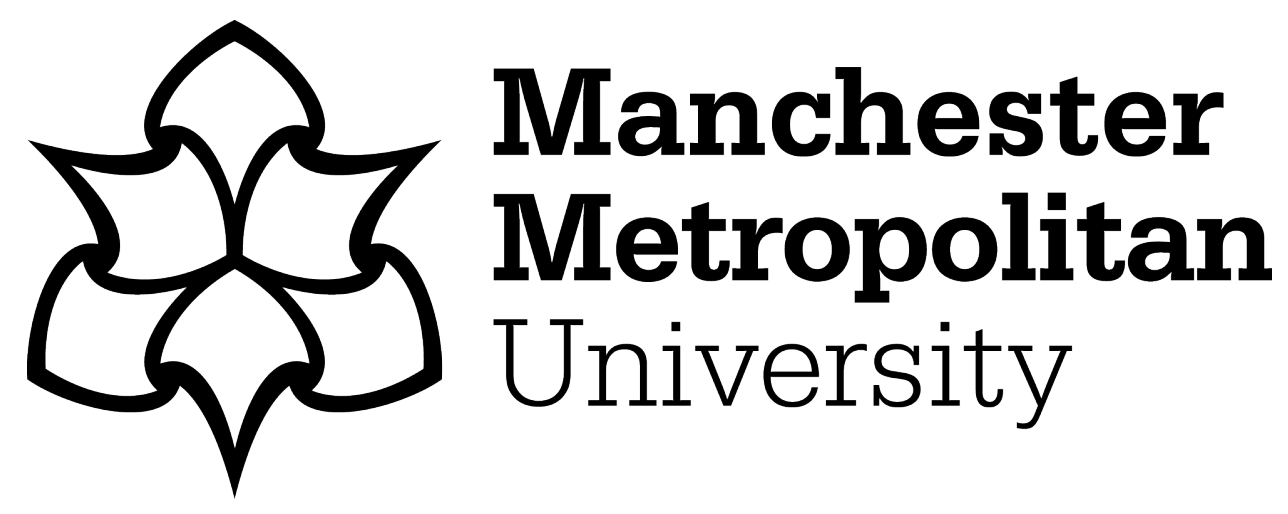

Niedderer, Kristina and Townsend, Katherine (2017) Editorial: Tradition and change: Craft between vernacular cultures and social innovation. Craft Research, 8 (2). pp. 163-167. ISSN 2040-4689

Downloaded from: https://e-space.mmu.ac.uk/622128/

Publisher: Intellect

DOI: https://doi.org/10.1386/crre.8.2.163_2

Please cite the published version 


\title{
Tradition and Change: Craft between vernacular cultures and social innovation
}

\author{
Kristina Niedderer and Katherine Townsend
}

Craft is regularly associated with tradition: traditions of making as well as traditions relating to social and cultural values and rituals. Traditions are often seen as something of the past that people cling to - sometimes to be cherished as a form of nostalgia, sometimes something to question and rebel against. But tradition is neither static nor inert: tradition grows, and the emerging values and behaviours of today may be the traditions and rituals of tomorrow. Bronner (2011) elucidates the underlying reasons for the continuing significance of traditions as rooted in the important social and psychological roles of tradition in everyday life. Enacted through cultural practices of rituals and customs, traditions are essential in the development of identity, heritage, and community. Craft is deeply rooted in traditions of "human and material agency [that cannot] be disentangled" (Malafouris 2013: 119) as an engine for constancy and renewal: swaying between the two defines its dynamic nature.

This issue supports the concept of craft as an intermediary between past, present and future making, by focusing on how craft practitioners, designers and makers create and relate traditions and innovations. In their article on traditions and vernacular cultures, Anna Kouhia and Pirita Seitamaa-Hakkarainen investigate and frame vernacular cultures through reliance on and understanding of the materiality of making. They identify three strategies for negotiating vernacular traditions: preservation, which concentrates on maintaining traditions; application, a strategy which allows for the mediation and hybridization of traditions; and transformation, for subverting and creating new traditions.

Patrick Dillon and Sirpa Kokko's article expands and demonstrates this thinking through six examples of vernacular cultures in the context of modernisation and cultural ecology in three countries. They highlight the transactional relationships between people and the environments as a process of continuity and change that shape culturally derived patterns and cultural traditions. Kofi Adjei, Eric Asante and Rexford Oppong explore 'the concept of mixed media ceramics in Ghana', an emerging craft practice that builds on the West African country's modern tradition of ceramics, established in the 1940s. Taking the hand manipulation of clay as a starting point, disparate materials and objects are integrated to produce novel, expressive sculptural forms. Developing the topic of clay between tradition and new technology in the form of brick sculpture, David Jones' review of Gwen Heeney's work offers a posthumous overview and perceptive analysis of her work. Heeney's work was outstanding in its scale and intensity of expression, uniting traditional techniques and visual elements with the use of new technologies and novel imagery to offer contemporary reflection as well as to support industry. 
Spyros Bofylatos further interrogates the power of craft not just to develop itself but also to help advance broader areas of concern such as sustainability. In discussing and drawing out the parallels of craft and service design approaches, he seeks to offer a new model for design for social innovation with focus on design for sustainability. Bofylatos identifies and relates four pairs: he suggest that intangible qualities within service design can be addressed through tacit knowledge of craft; heterogeneity of service and production can be re-read as distinctiveness and originality in the crafts; inseparability of production and consumption are akin and can be addressed through poeisis providing meaning and longevity in the light of perishability, which can be countered through the ideas of the 'ready to hand' and 'beauty in use' to embue value in objects.

Also focusing on sustainable development, Niina Väänänen, Minna Kaipainen, Leena Vartiainen and Sinikka Pöllänen investigate the practical and ethical perspectives of craft makers and their sense of responsibility through their paper focused on 'sustainable craft in practice'. The article insights following analysis of interviews with 16 craft practitioners working in Finland, to discover how they implement sustainability through their decisions and actions. Analysis of the qualitative data reveals a holistic system of sustainable craft, comprising three elements: sustainable practice, product and immaterial craft. The authors suggest that these intertwined elements were found to motivate and affect the practitioners and their products, which builds on Cox and Bebbington's (2014) argument that in addition to materials and production, sustainability and craft are also intertwined - for example, in corporative knowhow, the development of knowledge and skills, social responsibility and continuity of cultural and aesthetic experience.

Amy Twigger Holroyd's new book Folk Fashion: Understanding Homemade Clothes, reviewed by Timo Rissanen, reiterates the need for the business of fashion to incorporate longevity by harnessing the cultural and craft traditions of domestic sewing and knitting. Based on her PhD research, Twigger Holroyd's forward thinking framework for repairing, customizing and even re-knitting garments, presents the case for providing consumers with the agency to engage in the 'craft of use' (Fletcher 2016) by creatively extending the lifetime of a product. While Folk Fashion looks ahead, Erin Morton's For Folk's Sake: Art and Economy in Twentieth-Century Nova Scotia, reviewed by Fiona Hackney, considers folk art from a historical perspective, specifically how it became institutionalized in Nova Scotia in the period from the late 1960 s to the early twenty-first century in ways that were important to the ongoing historicizing of the provinces cultural identity. The book's examination of a diverse range of folk art artefacts, documentary film, press articles, state and government funding policies, and the testimonies of collectors, museums, arts professionals and self-taught artists, tells a compelling story about folk art in one locale which uncovers myths and informs understanding of folk art and culture elsewhere. Both publications support the current interest in Folk art and the revival in and re-evaluation of the role of amateur and domestic crafts, as exemplified by the Tate Britain's British Folk Art 
exhibition in 2014. The show acknowledged the rich, but elusive nature of folk art "often neglected in the story of art in Britain, the inclusion of these artists aims to reassess their position in art history." (Tate 2013) The re-evaluation by

J.W. Anderson reassessed the relationship between fashion and art in his exhibition, Disobedient Bodies, at The Hepworth, which is reviewed by Sarah Walker and Ania Sadkowska. By juxtaposing iconic garments from avant-garde designers with sculpture from the Hepworth and pieces from his own archive, Anderson invited the visitor to question to contemplate the body through classical and subverted interpretations via a series of 'domestic spaces', designed by 6 Architects. Disobedience was tangible in many of the exhibits, including early works by Barbara Hepworth and Henry Moore's which 'were radically irreverent towards the history of sculpture' and given equal footing with fashion, furniture, film and craft ceramics, thereby 'shredding some of the hierarchies or codes that keep creative worlds apart.' (Anderson 2017: 100). Laura Gardner addresses the theme of subverting the traditions and hierarchies present within the fashion design system in her review of the Everything and Everybody as Material: Beyond Fashion Design conference, held at the Swedish School of Textiles, University of Borås in collaboration with the School of Fashion and Textiles, RMIT University, Melbourne in June. The event was radical in its aim to highlight and challenge some of the issues raised by the commercial fashion system through the development of multidisciplinary, sustainable and participatory methodologies. Carefully curated in two parallel strands involving presentations, artists talks and performances, across a lecture theatre, design studio and exhibition space, the conference illustrated the power of textile/material agency, by questioning "not what a thing stands for but what it really brings forth in the world." (Malafouris, 2013: 149). The Remarkable Image features a moment from Linnea Bågander and Karolin Kent (2017) INSIDE/OUTSIDE - skin performance photographed by Jan Berg.

\section{A word of thanks}

We are delighted to present Volume 8.2 of Craft Research. As always, many people have been involved in the realisation of this issue. We wish to thank all our contributors, as well as those authors whose submissions we regrettably had to turn away. Our gratitude also extends to all our advisors as well as to our reviewers for their excellent work. Their constructive advice and feedback to authors is an essential part in fulfilling the developmental role of the journal and in advancing the field. We further wish to thank Intellect Publishers for their continued support for the journal, in particular our journal's manager, Bethan Ball, and her team.

Kristina Niedderer and Katherine Townsend August 2017 


\section{References}

Anderson, J.W. (2017) Disobedient Bodies: J.W.Anderson at The Hepworth, Wakefield, London: InOtherWords, OK-RM.

Bronner, S. J. (2011). Explaining Traditions: Folk Behavior in Modern Culture. Lexington: University Press of Kentucky.

Cox, E. and Bebbington, J. (2014), Craft and Sustainable Development: An Investigation, URL:

www.standrews.ac.uk/media/sasi/documents/Craft\%20and\%20Sustainable\%20Devel opment.pdf. Accessed 10 December 2014.

Fletcher, K. (2016), Craft of Use. Post-Growth Fashion. London \& New York:

Routledge.

Malafouris, L. (2013) How Things Shape the Mind: Theory of material engagement, Cambridge, Massachusettes and London, England: The MIT Press.

Tate (2013) British Folk Art, Press Release, 13 Dec, Available at: http://www.tate.org.uk/about/press-office/press-releases/british-folk-art - Accessed 14 August 2017. 